\title{
A novel gammaretroviral shuttle vector insertional mutagenesis screen identifies SHARPIN as a breast cancer metastasis gene and prognostic biomarker
}

\author{
Victor M. Bii ${ }^{1}$, Dustin T. Rae ${ }^{1}$ and Grant D. Trobridge ${ }^{1,2}$ \\ ${ }^{1}$ Washington State University College of Pharmacy, WSU Spokane, Spokane, WA, USA \\ ${ }^{2}$ School of Molecular Biosciences, Washington State University, Pullman, Washington, USA \\ Correspondence to: Grant D. Trobridge, email: grant.trobridge@wsu.edu \\ Keywords: insertional mutagenesis screen, breast cancer, gammaretroviral vector (YRV), metastasis, prognostic biomarker, Chro- \\ mosome Section \\ Received: October 02, $2015 \quad$ Accepted: October 14, $2015 \quad$ Published: October 25, 2015
}

This is an open-access article distributed under the terms of the Creative Commons Attribution License, which permits unrestricted use, distribution, and reproduction in any medium, provided the original author and source are credited.

\section{ABSTRACT}

Breast cancer (BC) is the second leading cause of malignancy among U.S. women. Metastasis results in a poor prognosis and increased mortality, but the molecular mechanisms by which metastatic tumors occur are not well understood. Identifying the genes that drive the metastatic process could provide targets for improved therapy and biomarkers to improve BC patient outcomes. Using a forward mutagenesis screen, BC cells mutagenized with a replication-incompetent gammaretroviral vector (YRV) were xenotransplanted into the mammary fat pad of immunodeficient mice. In this approach the vector provirus dysregulates nearby genes, providing a selective advantage to transduced cells to form metastases. Metastatic tumors were analyzed for proviral integration sites to identify nearby candidate metastasis genes. The YRV has a transgene cassette that allows for rescue in bacteria and rapid identification of vector integration sites. Using this approach, we identified the previously described metastasis gene WWTR1 (TAZ), and three other novel candidate metastasis genes including SHARPIN. SHARPIN was independently validated in vivo as a BC metastasis gene. Analysis of patient data showed that SHARPIN expression predicts metastasisfree survival after adjuvant therapy. Our approach has broad potential to identify genes involved in oncogenic processes for BC and other cancers. We show here it can identify both known (WWTR1) and novel (SHARPIN) BC metastasis genes.

\section{INTRODUCTION}

Breast cancer $(\mathrm{BC})$ is the second leading cause of mortality among women in the U.S. after lung cancer [1], and the lifetime risk of developing $\mathrm{BC}$ is estimated to be 1 in 8 women [2]. Estrogen and progesterone receptors (ER and PR) and HER2 (ERBB2) are used as biomarkers to aid in the histopathological classification and management of $\mathrm{BC}$ subtypes, with hormone receptor and ERBB2 positive tumors benefiting from targeted therapies. While these biomarkers have improved patient outcomes, metastatic disease often develops in $\mathrm{BC}$ patients and remains the leading cause of death. Therefore, a comprehensive understanding of metastatic genes and the pathways that facilitate metastatic tumor progression is essential.
Comparative genomic hybridization (CGH), proteomics, and deep sequencing have been used extensively to identify genes involved in BC [3-5]. These technologies have generated enormous amounts of data that highlight the complexity of $\mathrm{BC}$ disease progression, and have identified a wide spectrum of mutations, the vast majority of which probably have no significant biological relevance $[6,7]$. The causal driver mutations that are selected for during tumorigenesis are difficult to identify as they occur alongside many non-pathogenic passenger mutations [5, 8-10].

Retroviral insertional mutagenesis screens are a proven method to identify cancer genes due to the ability of vector proviruses to integrate into the host genome and dysregulate nearby genes [11]. This can occur by 
several well-known mechanisms including enhancer activation [12]. Cell clones with a vector provirus near genes affecting oncogenic processes that have a selective advantage will be enriched over time. The mapping of viral insertion sites in tumors identifies genomic loci that have genes that mediate cancer progression [11]. Retroviral mutagenesis screens have greatly improved our understanding of cancer and can be used specifically to identify driver genes from passenger genes that do not mediate cancer progression. This is because proviruses that dysregulate a nearby gene and thus alter the phenotype also tag the gene that is dysregulated. In the cell clone with this integrant other passenger mutations can accumulate, but they are not tagged. Thus, unlike deep sequencing approaches, retroviral mutagenesis allows analysis of the mutations that drive the cancer and ignores other accumulated mutations.

Replicating gammaretroviruses and transposons have been widely used to identify driver mutations in cancer studies $[13,14]$ but these techniques have several limitations. Replicating viruses have the potential to cause secondary integration(s) that make it difficult to identify true causal driver genes. Screens that use replicating retroviruses are also limited to tissues and cell types that are permissive for replication of the virus. Because of this, the majority of screens have been performed in mouse hematopoietic cells or mouse mammary cells. Transposons allow mutagenesis of essentially any tissue and have expanded the use of mutagenesis screens. However, a major drawback of transposon approaches is the time it takes to generate the germline transgenic or knockout lines used, and to combine multiple alleles into the same background [15]. Another limitation of transposon mutagenesis is that multiple transposition events complicate the identification of causative mutagenic events [15]. Replication-incompetent retroviral vectors have been used to identify early cancer-driving events [16, 17]. When integrated in the genome they do not create secondary insertions that may mask the identification of driver genes. Also, the level of mutagenesis can be carefully controlled by adjusting the multiplicity of infection (MOI). Importantly, replication-incompetent vectors can cause cancer, which was unfortunately been observed in previous gene therapy clinical trials where a replication-incompetent gammaretroviral vector $(\gamma R V)$ caused leukemia $[18,19]$. By pseudotyping $\gamma \mathrm{RVs}$ with the vesicular stomatitis virus glycoprotein envelope, these vectors can be used to mutagenize essentially any cell type. Thus, $\gamma$ RVs could be used in forward mutagenesis screens to identify driver genes for any type of cancer. Depending on how the screen is designed, genes that mediate oncogenic processes such as invasion, migration, or metastasis could be identified using replicationincompetent $\gamma$ RVs.

To identify retroviral or transposon integration sites, the majority of screens have used PCR-based methods
[11]. PCR has had significant success in identifying provirus insertions but technical challenges associated with PCR reduce the efficiency of provirus detection [11, 20]. There is a lack of sensitivity in detecting integrations events that are rare, and when restriction digests are used, insertions with small fragment lengths can be underrepresented and short sequence lengths can complicate identifying integration sites. Also, PCR amplification of a given region cannot occur if one or more primer sites is lost or distantly located [11]. To overcome PCR challenges, a high-throughput shuttle vector rescue method can be used which is capable of producing sequence lengths that are longer than those produced by PCR methods and allow for efficient identification of provirus integrations [17, 21].

Here, we used a $\gamma R V$ shuttle vector mutagenesis screen to identify driver genes involved in the progression of metastasis in BC. $\gamma \mathrm{RV}$ are known to be more genotoxic than lentivirus vectors [22], which is desirable for insertional mutagenesis screens. We report for the first time the use of a $\gamma \mathrm{RV}$ shuttle vector approach to identify genes that drive $\mathrm{BC}$ metastasis. We identified four genes including two genes previously implicated in BC metastasis. We also show for the first time that SHARPIN is a $\mathrm{BC}$ metastasis gene and that it is a prognostic biomarker for risk associated with distant metastasis and survival of patients after treatment.

\section{RESULTS}

\section{Production of human metastatic BC tumors in mice}

To efficiently cause insertional mutagenesis, we designed a replication-incompetent $\gamma \mathrm{RV}$, CL-SGN-OK (Figure 1A) containing murine leukemia virus long terminal repeats and a strong internal spleen focus forming virus promoter that drives the expression of an enhanced green fluorescent protein (EGFP)-neomycin fusion protein and is known to dysregulate nearby genes [22]. The vector also includes a bacterial origin of replication and kanamycin resistance gene to allow identification of integration sites by rescue of shuttle vector plasmids in E.coli. A neomycin cassette transgene allows for selection of transduced cells using G418. In this screen, MDAMB-231 cells were transduced and used in an orthotopic xenograft model $[23,24]$ to identify genes that confer $\mathrm{BC}$ cells with a selective advantage to metastasize. Prior to injection, $\gamma \mathrm{RV}$ transduced cells were selected for using G418 for 16 days and $>94 \%$ selected cells were obtained (Figure 1B). Mutagenized MDA-MB-231 and untransduced control cells were co-transplanted with bone marrow derived human mesenchymal stem cells (hMSCs) at a ratio $1: 1$ orthotopically into the mammary fat pad of immunodeficient of mice (Figure 1C). The mutagenized or 
Table 1: Candidate BC metastasis genes

\begin{tabular}{|c|c|c|c|c|c|}
\hline Chr. ${ }^{\text {a }}$ & Gene $^{\text {b }}$ & Tissue $^{c}$ & Integration in/near gene $(b p)^{d}$ & Expression $^{\mathrm{e}}$ & $p$-value ${ }^{\mathrm{f}}$ \\
\hline $8^{g}$ & SHARPIN & liver, kidney & In & Over & 0.001 \\
\hline 3 & WWTR 1 & $\begin{array}{l}\text { lung, liver, kidney, } \\
\text { lymph node }\end{array}$ & In & Over & 0.006 \\
\hline 11 & RIN1 & liver & 4212 & Under & 0.01 \\
\hline $8^{\mathrm{g}}$ & $M A F 1$ & liver, kidney & 424 & Over & 0.046 \\
\hline
\end{tabular}

a Chromosome with vector provirus, ${ }^{\mathrm{b}}$ Gene in or near vector provirus, ${ }^{\mathrm{c}}$ Tissue from which the metastasis was isolated, ${ }^{\mathrm{d}}$ Indicates whether the vector provirus integrated within a gene or near a gene transcription start site within the distance indicated, ${ }^{\mathrm{e}}$ Expression of the candidate gene in $\mathrm{BC}$ patient tissue from Oncomine $\mathrm{C}^{\mathrm{TM}}$ analysis, ${ }^{\mathrm{f}} \mathrm{p}^{\mathrm{f}}$-value from Oncomine ${ }^{\mathrm{TM}}$ analysis of expression between $\mathrm{BC}$ patient tissue and unaffected tissue, ${ }^{\mathrm{g}}$ The same shuttle vector provirus integration site

control cells were transplanted into different mice. hMSCs have been shown to enhance engraftment and increase the establishment of metastasis as a result of secretion of CCL5 (RANTES) in a mouse xenotransplant model [25]. Seven out of ten injected mice efficiently developed primary tumors approximately nine weeks post-injection (Figure 1C). Once the primary tumor reached a mean diameter of $1.5 \mathrm{~cm}$, mice were euthanized and tissues (liver, kidney, lung, lymph node, bone, and spleen) were removed and metastatic tumors were isolated from liver, kidney, lung and lymph node (Table 1).

\section{Analysis and identification of $\gamma \mathrm{RV}$ integration sites in metastatic tumors}

To identify the provirus integration sites, genomic DNA isolated from the in vivo metastatic tumors was analyzed for provirus integration sites using a shuttle vector rescue approach (Figure 2) [17]. We identified vector insertion sites from 15 metastatic tumors from six mice that developed primary tumors. Sequence reads were analyzed and mapped to the human genome using the vector integration site analysis (VISA) bioinformatics program [26] to identify the provirus integration sites and nearby genes. The LTR-chromosomal junction was identified and location of the provirus integrations were mapped relative to genomic features (hg19) using the University of California Santa Cruz (UCSC) genome browser (Supplementary S1) [27]. We identified eight unique integration sites in our screen that could be aligned to the human genome using strict criteria $[17,26]$ and were considered for further analysis. These unique integrations had varied capture frequencies in metastatic tumors ranging from 1-47 times (Supplementary Table $\mathrm{S} 1)$. Only genes within $5 \mathrm{~kb}$ of the provirus integration were considered for further analysis. All $\gamma \mathrm{RV}$ integrations were near transcription start sites (TSS) (Table 1, Supplementary S1 and Supplementary Table S1). This finding was expected as $\gamma \mathrm{RV}$ are known to integrate near TSS, promoter regions and $\mathrm{CpG}$ islands [21].

\section{Meta-analysis of genes identified by shuttle vector identifies candidate $\mathrm{BC}$ metastasis genes}

We reasoned that by combining the strength of our screen with publicly available gene expression data from patients, we could improve the ability of this approach to identify clinically relevant driver genes. To identify candidate genes that might significantly contribute to $\mathrm{BC}$ metastasis in patients, we explored the expression of all genes within $5 \mathrm{~kb}$ of vector proviruses in $\mathrm{BC}$ patients using data derived from patient tumor samples in the Oncomine ${ }^{\mathrm{TM}}$ database [28]. Oncomine ${ }^{\mathrm{TM}}$ metaanalysis of 22 independent $\mathrm{BC}$ gene expression datasets from nine independent studies [25, 29-37] were used to evaluate genes within $5 \mathrm{~kb}$ of provirus integration sites which identified four genes whose expression was significantly different between $\mathrm{BC}$ tissues and normal breast tissues from the same patient tissue type (Table 1 and Supplementary S2). SHARPIN (SHANK-associated $\mathrm{RH}$ domain interacting protein) was the top candidate gene that was overexpressed in $\mathrm{BC}$ tissue relative to normal control tissues of the same patient tissue type and had a $p$-value $=0.001$ across all 22 datasets. $W W T R 1$ (WW domain containing transcription regulator 1 ) had a $p$-value $=0.006$. Other promising $\mathrm{BC}$ metastasis genes were RIN1 (Ras and Rab interactor 1) $(p=0.01)$ and $M A F 1$ (MAF1 homolog) $(p=0.046)$. All genes were overexpressed in BC tumors except RIN1 which was underexpressed. Our screen identified the recently described BC metastasis gene WWTR1 [38] and a known BC tumor suppressor gene RIN1 [39] supporting the power of our approach. Our screen also identified novel candidate BC metastasis genes SHARPIN and MAF1. SHARPIN was overexpressed in metastatic tumors compared to primary tumors (Supplementary S3).

As previously reported, patients with ERBB2 negative $\mathrm{BC}$ have poor clinical outcomes characterized with a higher incidence of metastases [40]. We assessed if the expression levels of top candidate gene SHARPIN correlates with ERBB2 BC clinico-pathological 
A.

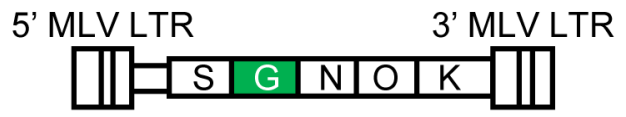

C.

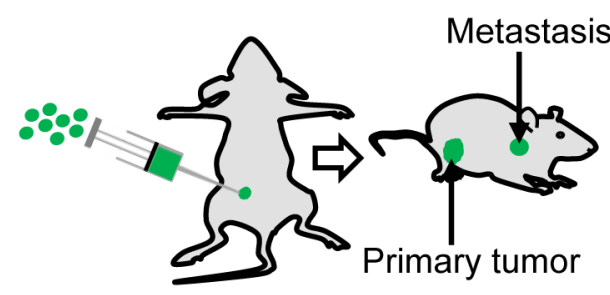

B.

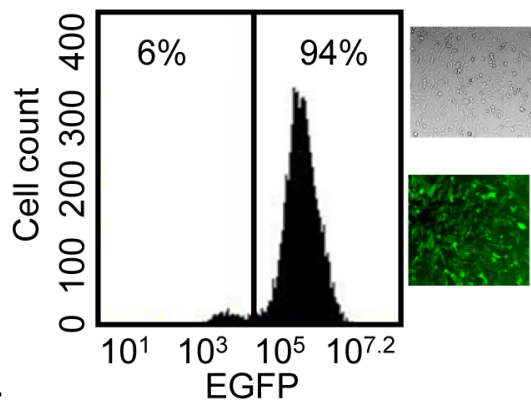

Figure 1: Efficient establishment of mutagenized BC cells. A. The $\gamma R V$ shuttle vector construct CL-SGN-OK has murine leukemia virus derived long terminal repeats (MLV LTR) with strong enhancers in the U3 region. A strong internal spleen focus-forming virus (S) promoter drives the expression of an EGFP-Neomycin fusion protein $(\mathrm{G})$ to track transduced cells and a neomycin phosphotransferase $(\mathrm{N})$ transgene to select for transduced cells. The R6K $\gamma$ bacterial origin $(\mathrm{O})$ of replication and kanamycin $(\mathrm{K})$ resistance gene for rescuing plasmids in E. coli allow for identification of virus integration by shuttle vector rescue approach. B. Transduced and G418-selected MDAMB-231 cells. The $\gamma$ RV shuttle vector transduced MDA-MB-231 cell culture with over $94 \%$ transduced cells after G418 selection used for the metastasis screen. C. Orthotopic xenograft model. $1 \times 10^{6} \gamma \mathrm{RV}$ transduced or untransduced MDA-MB-231 cells were orthotopically injected into mammary fat pad of 8 week old female NOD.Cg-Prkdc ${ }^{\text {scid }} I 12 \mathrm{rg}^{\text {tmlWjil}} / \mathrm{SzJ}$ (NSG) mice. D. Primary tumor growth. Seven out of ten mice developed primary tumors and tumor development was measured using external calipers to generate tumor growth curve.

A.

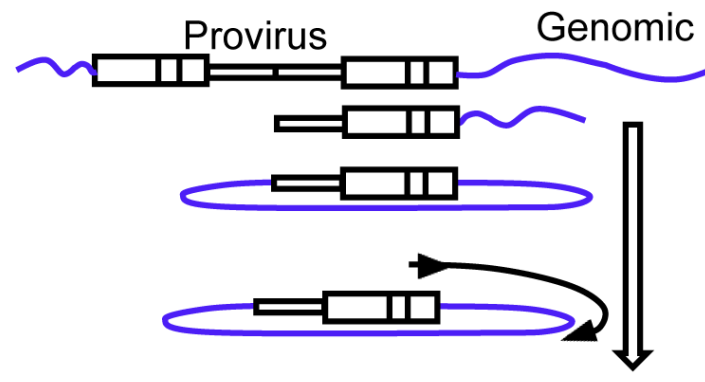

- Shear and polish ends

- Ligate

- Transform in E.coli

- Sequence LTR: chromosome junction to identify integration sites

B.

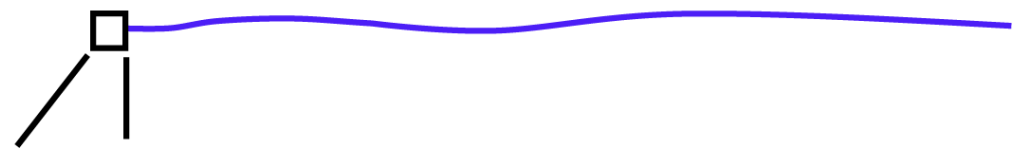

TTTCAtcccagccgttccagacctccgggeccgtgtcccatctacctgcctta

LTRgenomic DNA query used to align to the human genome

Figure 2: Identification of $\gamma \mathbf{R V}$ integration sites in metastatic tumors. A. Shuttle vector rescue approach. Efficient recovery and identification of $\gamma R V$ vector integration sites was determined by a high-throughput shuttle vector rescue approach. Shuttle vector rescue was performed on genomic DNA obtained from metastatic tumors. B. Identification of provirus integration site. The genomic DNA query sequence (Lowercase letters-underlined) at the LTR (Uppercase letters)-chromosomal junction is aligned to the human genome to identify the integration site. 
characteristics by interrogating the Gluck et al dataset [30] using Oncomine ${ }^{\mathrm{TM}}$. The gene expression pattern included $119 E R B B 2$ negative and $33 E R B B 2$ positive $\mathrm{BC}$ tissues. SHARPIN expression was significantly elevated in ERBB2 negative compared to $E R B B 2$ positive tumor samples ( $p$ $<0.05$ ) (Figure 3). This result shows that SHARPIN is overexpressed in $\mathrm{BC}$ patient tumors and correlates to $\mathrm{BC}$ clinico-pathological features such as ERBB2 expression.

\section{Candidate BC metastasis genes are recurrently altered in $\mathrm{BC}$ patients}

Regions of recurrent genomic mutations including amplifications have been implicated in $\mathrm{BC}$ progression $[41,42]$. It is important to combine genomic mutations and gene expression patterns in clinical stratification of $\mathrm{BC}$ patients. The cBioportal cancer genomics tool was used to evaluate the genetic alterations of the potential candidate genes in $\mathrm{BC}$ patient samples [43, 44]. We evaluated different genetic alterations including mRNA expression (upregulation and downregulation) and copy number alterations (deletion and amplification) in the TCGA dataset [6] to determine if they relate to BC progression. We chose to use the TCGA dataset because of its large sample size ( 825 patient tumor samples) that includes all four of the candidate $\mathrm{BC}$ metastasis genes. For comparison, we also evaluated TP53 and BRCA1, two mutated genes found at high frequency in most BC patients. We observed that of the four candidate genes, SHARPIN was the most frequently altered gene $(20 \%)$ followed by MAFl (16\%), WWTRl (7\%), and RIN1 (6\%) (Figure 4A). Of SHARPIN altered BC samples, 21\% were ER negative, $75 \%$ ERBB2 negative and 54\% were nodal tumors (Figure 4B). These data demonstrate that our $\gamma \mathrm{RV}$ approach identified recurrently altered genes in $\mathrm{BC}$ using independent publicly available patient data. We further showed that SHARPIN can be a potential biomarker for stratifying BC patients (Figure 3). This result independently correlated with Oncomine ${ }^{\mathrm{TM}}$ analysis of Gluck et al. [30] BC data that show patients with ERBB2 negative $\mathrm{BC}$ significantly overexpressed SHARPIN.

\section{SHARPIN knockdown reduces metastasis of BC cells in vivo}

SHARPIN is modulator of the NF-kB pathway, and SHARPIN up-regulation promotes cell proliferation, migration, invasion and chemoresistance in prostate cancer by affecting the downstream targets survivin and livin [45]. SHARPIN has recently been shown to be involved in $\mathrm{BC}$ progression [46] but it has not previously been shown to affect $\mathrm{BC}$ metastasis. We first explored the effects of SHARPIN on clonogenicity. To knockdown SHARPIN expression in $\mathrm{BC}$ cells, we used a stable inducible lentiviral shRNA system with a tetracycline (Tet)regulated (Tet repressor (TetR)-responsive) promoter that allows for doxycycline inducible expression of shRNAs [47]. This inducible shRNA system allows analysis of SHARPIN effects on BC cells by comparing isogenic BC cell populations using doxycycline-induced SHARPIN knockdown. MDA-MB-231 cells were stably transduced and exposed to doxycycline to induce SHARPIN shRNA for 12 days. Knockdown of SHARPIN in MDA-MB-231 cells was confirmed by Western blot (Figure 5A). Clonogenic assay confirmed that SHARPIN knockdown inhibited the clonogenicity of BC cells by $42 \%$ compared with their respective control cells $(p<0.01)$ (Figure 5B). This result indicates that SHARPIN knockdown decreases

\section{A}

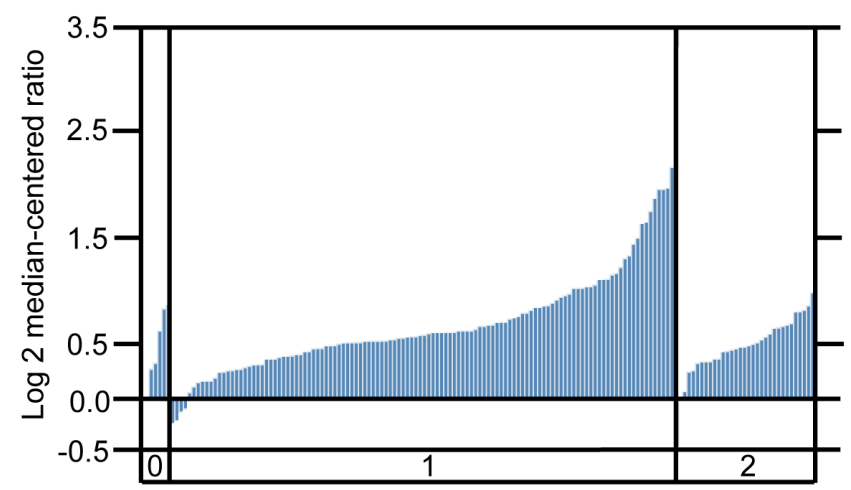

B

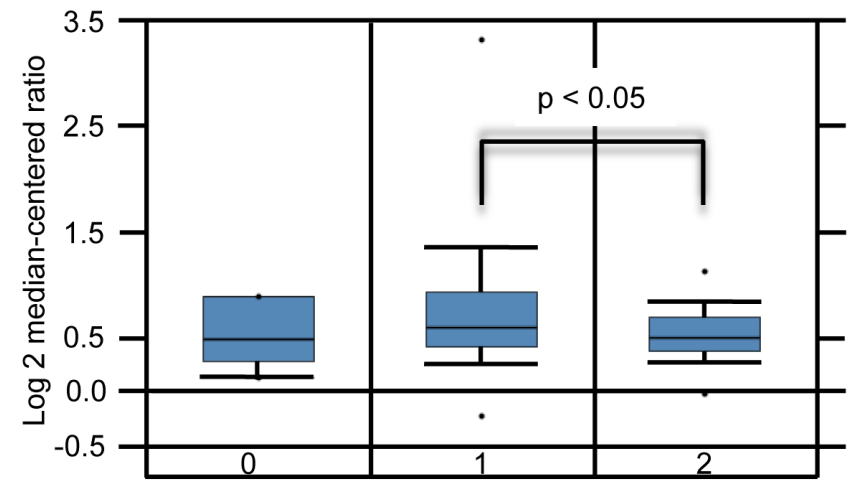

0. No value (6) 1. ERBB2 negative (119) 2. ERBB2 positive (33)

Figure 3: SHARPIN expression increases in ERBB2 negative BC. A. Waterfall plot of individual patients. B. Box plots of SHARPIN expression for invasive ductal carcinoma. Data derived from Oncomine ${ }^{\mathrm{TM}}$ Gluck et al. 2006 dataset with 158 samples measuring mRNA probe_set for SHARPIN Reporter ID: 1621 


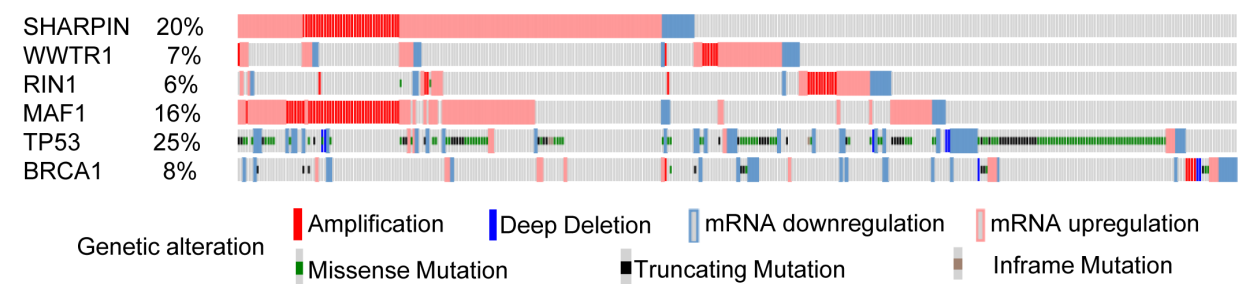

B

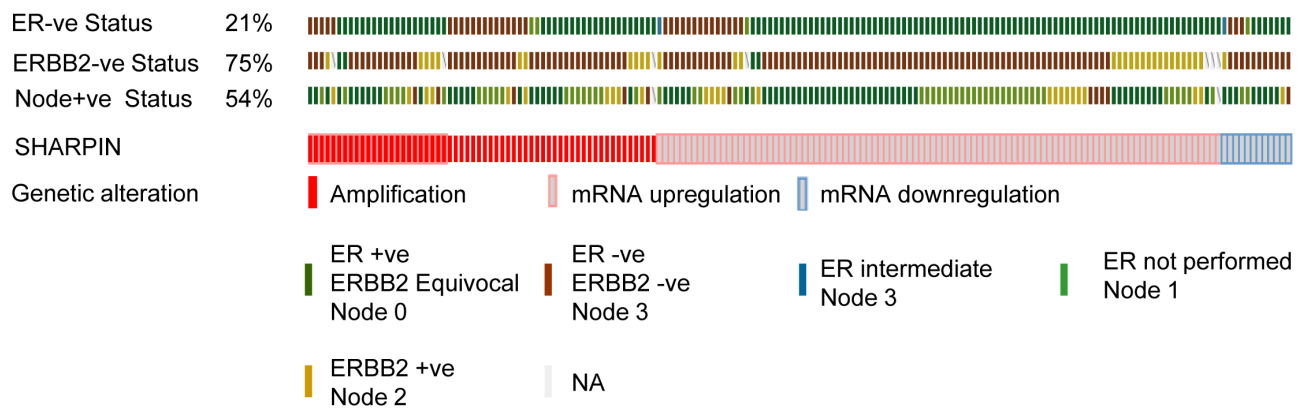

Figure 4: cBioportal analysis showing distinct genetic alteration in candidate genes in BC patients. Each patient sample is represented by a bar and each color indicates specific genetic alteration as indicated. Only patients with alterations were shown. As controls, genetic alteration of TP53 and BRCA1, frequently altered genes in BC patients is also shown. The frequency of gene alteration is represented as a percentage. A. Genetic alteration in samples expressing candidate genes. B. The BC clinico-pathological features such as ERBB2 negative (75\%), ER negative (21\%), and nodal positive tumors (54\%) for patients with SHARPIN mutations.

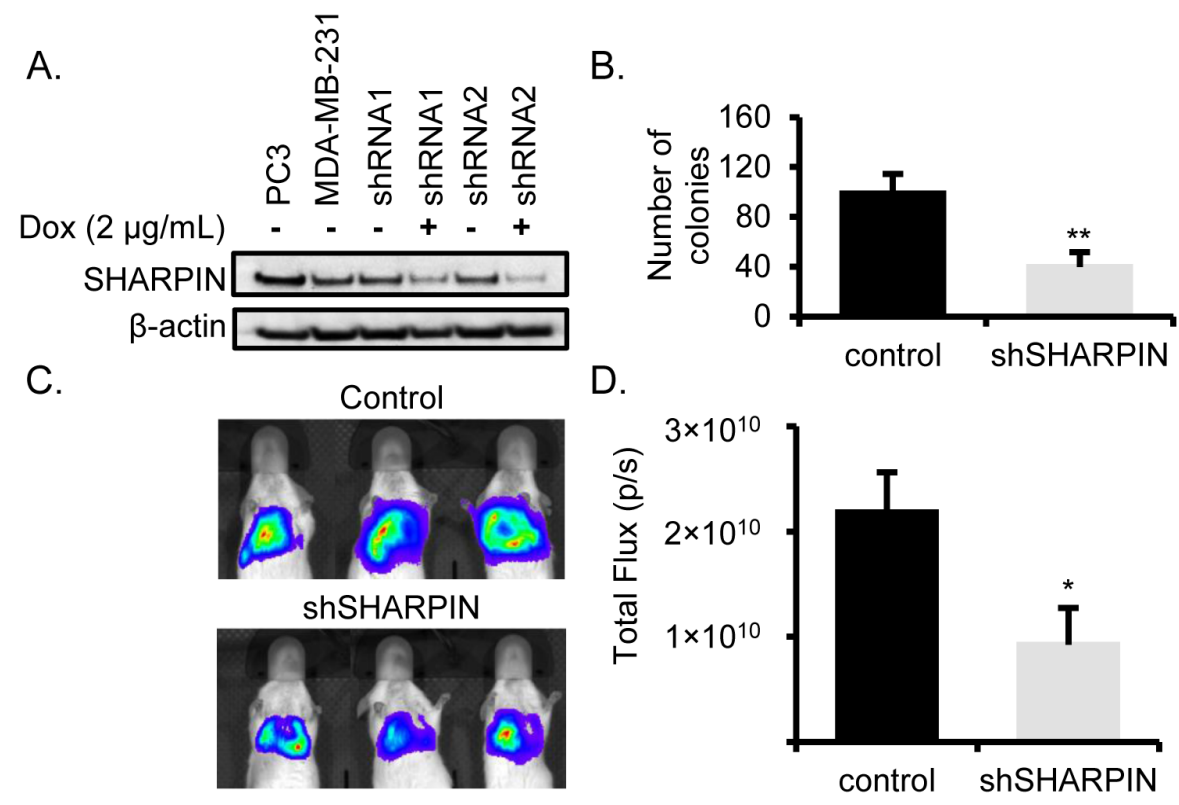

Figure 5: SHARPIN knockdown inhibits BC metastasis. A. Inducible SHARPIN shRNA knockdown. The PC3 cell line (positive control), MDA-MB-231, SHARPIN shRNA 1 and 2 MDA-MB-231 ( \pm Dox) were examined for the expression of SHARPIN by western blotting. $\beta$-actin served as a loading control. B. SHARPIN promotes BC clonogenicity. MDA-MB-231luc2 cells stably expressing luciferase were transduced with doxycycline inducible SHARPIN shRNA 2 to knockdown SHARPIN and their proliferation potential was tested using clonogenic assays before injection into immunodeficient mice. SHARPIN knockdown significantly inhibited MDA-MB-231luc2 proliferation in vitro. Data are the mean, error bars represents the SD. $(* * p<0.01)$. C. Representative BLI image of lung metastasis depicting photon flux emitted at week 8 of control and shSHARPIN after $1 \times 10^{6}$ SHARPIN shRNA 2 transduced MDA-MB-231luc2 cells were injected via tail vein into immunodeficient mice. D. BLI of lung metastasis at week 8 showing the total photon flux emitted (photon/ sec). Control $(n=3)$ and $\operatorname{shSHARPIN}(n=5)$. Data are the mean, $\pm \operatorname{SEM}\left({ }^{*} p<0.05\right)$. 
the clonogenicity of BC cells.

Metastasis occurs when cancer cells adapt to a tissue microenvironment that is distant from the primary tumor $[48,49]$. For in vivo validation of SHARPIN in BC metastasis, we used a previously described metastasis assay in which MDA-MB-231 cells were injected into the lateral tail vein of mice to evaluate metastasis of $\mathrm{BC}$ cells to the lung [50]. Inducible SHARPIN shRNA knockdown transduced BC cells encoding a luciferase reporter gene (MDA-MB-231luc2) were injected intravenously into immunodeficient mice. SHARPIN knockdown was induced by doxycycline administration via drinking water. A non-invasive bioluminescence imaging (BLI) was used to assess the establishment of metastatic tumors in the lungs [51]. At eight weeks, BLI was performed on the animals to assess lung metastasis. Quantification of bioluminescence intensity in animals with SHARPIN knockdown BC cells showed that the metastatic development of tumors was significantly reduced ( $p$-value $<0.05$ ) (Figure 5C, 5D and Supplementary S4). This data shows that silencing SHARPIN reduces the metastatic ability of $\mathrm{BC}$ cells in vivo, validating $S H A R P I N$ as a $\mathrm{BC}$ metastasis gene.

\section{SHARPIN is a potential $\mathrm{BC}$ prognostic biomarker}

ER, PR, and ERBB2 are the most widely used biomarkers for prognosis and treatment prediction in BC patients. For example the use of ERBB2 as a biomarker has been successful for treatment of ERBB2 overexpressing tumors with trastuzumab (Herceptin) [52]. Despite this remarkable clinical response, there is a need for more biomarkers for efficient BC treatment due to the heterogeneity of BC. Therefore, we assessed the prognostic value of SHARPIN expression in predicting the clinical outcome in BC patients using the publicly available SurvExpress database [53]. This tool stratifies patients into low and high-risk groups based on differential gene expression and derives patient Kaplan-Meier survival curves. To assess whether our findings would have a clinical significance, we correlated SHARPIN expression and the development of metastasis. We used the data of Kao et al. [54] which examined the metastasisfree and overall survival of BC patients $(n=327)$ after treatment with long-term follow-up to analyze the effect of SHARPIN expression on BC metastasis. Expression of SHARPIN affected metastasis-free survival in patients ( $p$ $<0.005$, Concordance Index $=55.3$, Risk Groups Hazard Ratio $=1.87)($ Figure 6A). BC patients expressing high levels of SHARPIN had a shorter metastasis-free survival than BC patients expressing low levels of SHARPIN. When a known biomarker ERBB2 [55] was compared with SHARPIN it showed a similar statistical significance $(p<0.004)$ for metastasis-free survival on the same dataset (Figure 6B). When a combination of these two genes were used, the prediction of metastasis free survival was significantly increased $(p<0.0006)$ (Figure 6C). The ability of SHARPIN to predict metastasis free survival was also confirmed using an independent patient dataset by Chin et al. [56] $(p<0.05)$ (Supplementary S5). This result shows that SHARPIN expression is a prognostic indicator for survival in BC patients.

We also investigated whether SHARPIN can be used in combination with other novel candidate genes that we have identified in our retroviral mutagenesis screen as prognostic biomarkers for metastasis free survival in BC patients. To identify gene sets that would efficiently predict clinical outcome, we analyzed prognostic values for each gene independently as well as in different combinations (2, 3, and 4- genes) (Supplementary Table S2). The combinatorial expression of WWTR1, MAF1 and RIN1 modestly improved the ability to predict metastasis free survival in BC patients ( $p=0.0029$, Concordance Index $=59.88$, Risk Groups Hazard Ratio = 3.54).

\section{DISCUSSION}

Here, we describe a novel mutagenesis screen using a replication-incompetent $\gamma \mathrm{RV}$ shuttle vector to identify BC metastasis driver genes. Our $\gamma R V$ shuttle vector approach has several advantages. It is highly genotoxic, allows for efficient detection of provirus integration sites without technical challenges associated with PCR and can be used to mutagenize essentially any mammalian cell type due to its broad tropism which is mediated by the vesicular stomatitis virus glycoprotein envelope pseudotype. To our knowledge, we are the first to perform a retroviral insertional mutagenesis screen to identify metastatic driver genes involved in $\mathrm{BC}$ progression. The ability to transduce cells with a low MOI and then eliminate untransduced cells using G418 reduces the number of cells with multiple integrations, and thus reduces the potential to identify passenger genes. In the present study we identified fewer insertions and identified a higher frequency of genes that were dysregulated in patients than we previously identified in a prostate cancer study where a lentiviral vector was used at a relatively high MOI without G418 selection to eliminate untransduced cells [17].

Our screen identified a known BC metastasis gene $W W T R 1$, a known BC tumor suppressor gene RIN1, and novel candidate genes SHARPIN and MAF1 that have not been previously shown to affect BC metastasis. The four genes we have identified in our screen had previously described functions related to RNA regulation ( $M A F 1)$, epigenetic modification and regulation of cell migration (RIN1), and cell proliferation, migration and invasion (SHARPIN). WWTR1 has recently been shown to be involved in $\mathrm{BC}$ metastasis progression and development of drug resistance tumors in BC patients [38]. Also, RIN1 has been identified as a breast tumor suppressor gene [39]. These findings validate our novel shuttle vector approach and the use of a $\gamma \mathrm{RV}$ mutagenesis screen to identify 
candidate BC metastasis driver genes.

Meta-analysis of gene expression profiles have been used in BC studies to identify genes that are important for prognosis and treatment [57]. In our analysis, we utilized Oncomine ${ }^{\mathrm{TM}}$ to prioritize candidate genes for validation.
Comprehensive meta-analysis using Oncomine ${ }^{\mathrm{TM}}$ revealed that the expression of candidate genes favored disease progression (Table 1 and Supplementary S2). Particularly SHARPIN which was highly expressed in metastatic (Supplementary S3) and ERBB2 negative (Figure 3) breast

A.

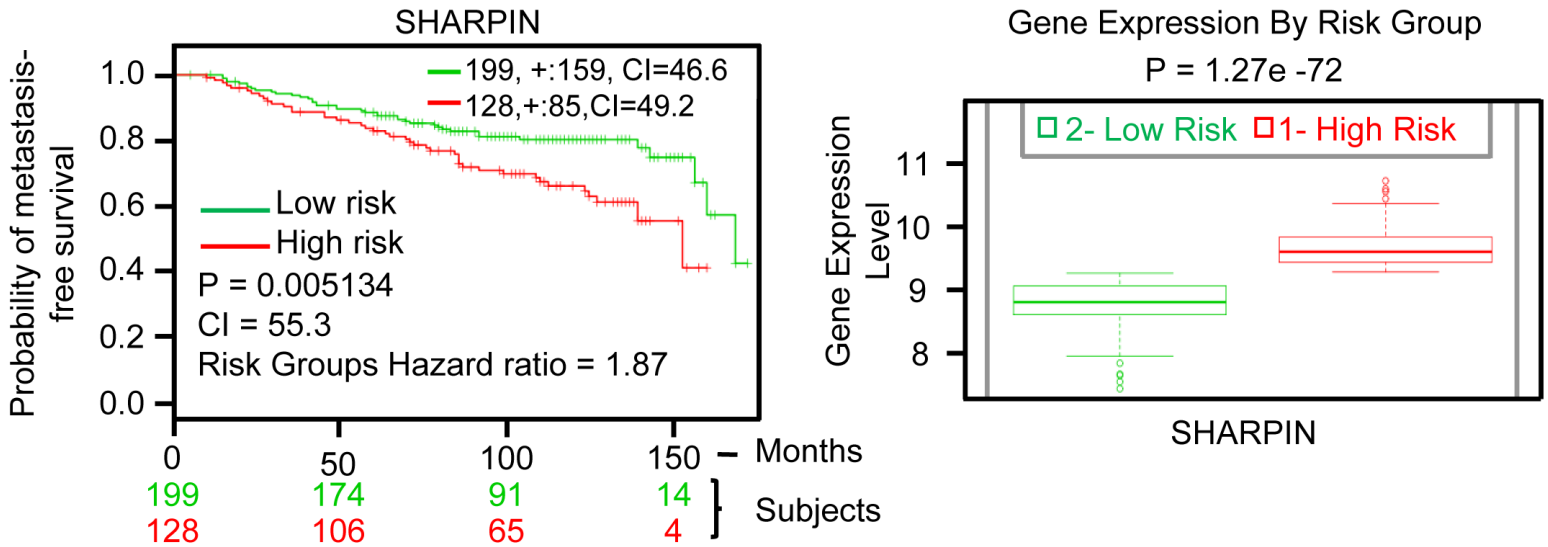

B.

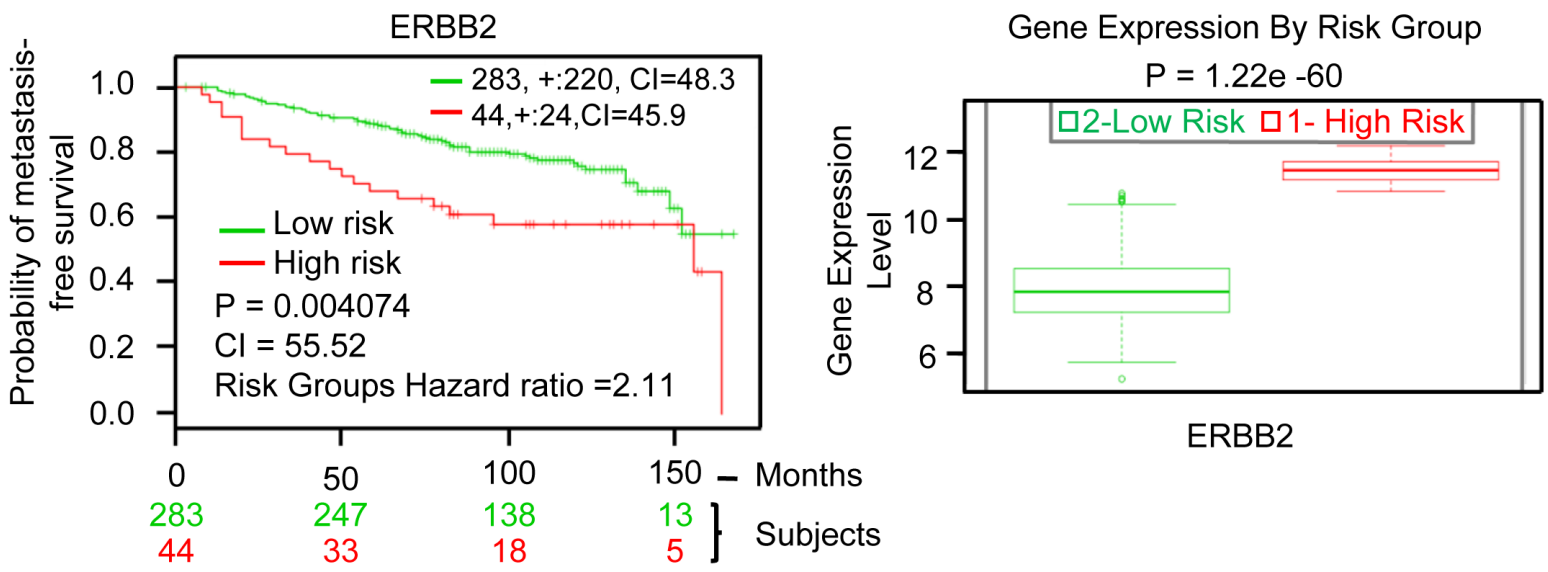

C.
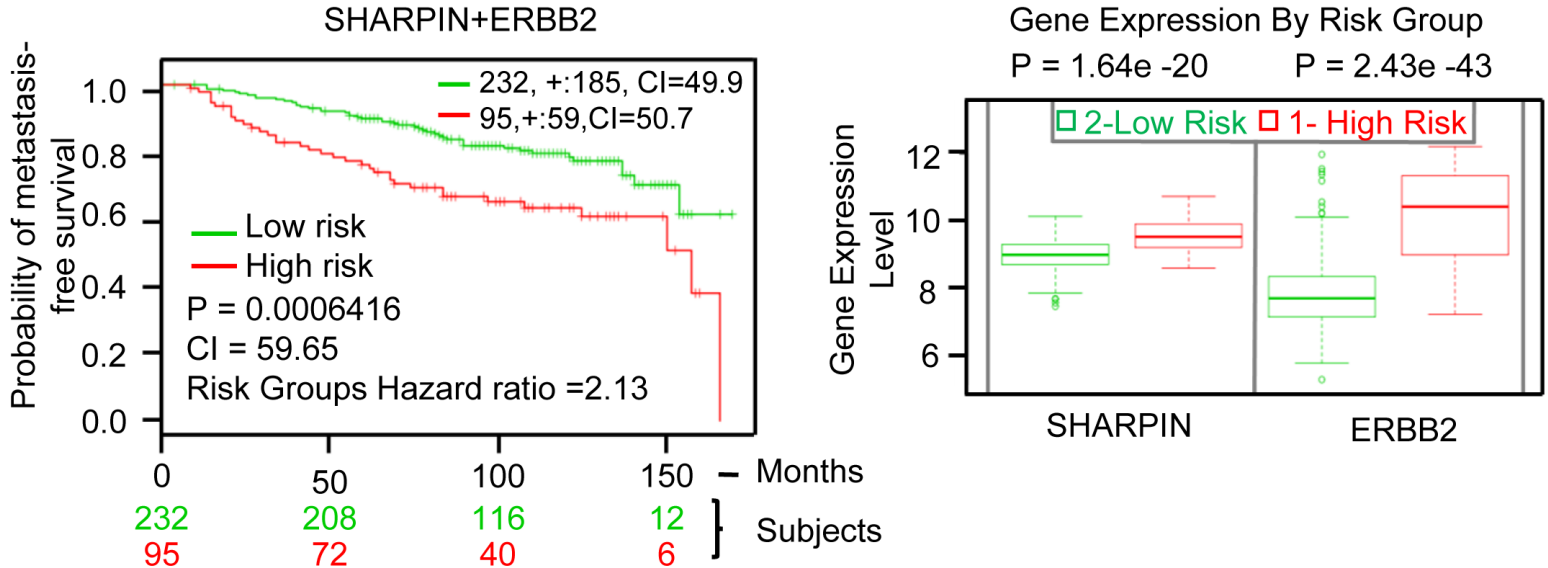

Figure 6: SHARPIN gene expression in BC patients predicts clinical outcomes. A. SHARPIN. B. ERBB2. C. SHARPIN and ERBB2 combination. Kaplan-Meier survival curves and Box-plots generated using SurvExpress biomarker validation tool showing the ability of gene expression to predict metastasis-free survival outcome in BC patients using cohorts from datasets generated by Kao et al., 2011. The insets in top right represents number of individuals, number censored, and concordance index (CI) of each risk groups and '+' represent censoring samples. High and low risk groups are shown in red and green respectively. Box-plots show expression levels and p-values resulting from t-test of the difference expression between high risk (red) and low risk (green) groups in BC patients. 
tumors. The cBioportal web tool shows genetic alterations in BC linked to cancer histopathology [58]. cBioportal suggested that the $\mathrm{BC}$ candidate genes we identified were genetically altered by copy number variations, mutations, deletions, mRNA upregulation or downregulation in BC patients (Figure 4A). These mutations can be combined with gene expression patterns to stratify $\mathrm{BC}$ patients according to known BC clinico-pathological features such as ER, ERBB2, and lymph node involvement (Figure 4B). These independent analyses show that our $\gamma R V$ mutagenesis approach has the ability to identify candidate $\mathrm{BC}$ genes and/or prognostic markers for BC.

In our in vivo xenograft metastasis model, SHARPIN knockdown inhibited metastasis. SHARPIN has been previously shown to have significant elevation of expression in $\mathrm{BC}$ in comparison to non-tumor breast tissues [46], but to our knowledge we are the first to show that SHARPIN is a BC metastasis gene. Additionally, we have shown the correlation between BC clinicopathological features ER, ERBB2 and lymph node with SHARPIN expression. Previous studies have also been performed in in vitro and in vivo mice models on the effects of Sharpin, such as dysregulation of immune system [59], regulation of NF-kB and apoptosis [6062], TNF- activation of NF-kB [63, 64], control of inflammatory reaction in viral-induced infection [65] and integrin regulation [66]. As a modulator of the NF$\mathrm{kB}$ pathway, SHARPIN up-regulation promotes cell proliferation, migration, invasion and chemoresistance in prostate cancer by affecting the downstream targets survivin and livin [45]. It is highly likely that similar pathways could be involved in BC metastasis and understanding the molecular mechanisms responsible for SHARPIN expression may lead to improved therapies for BC patients.

Interestingly, all four genes we identified (SHARPIN, WWTR1, MAF1 and RIN1) were able to predict metastasisfree survival in BC patients. The association of SHARPIN expression and metastasis-free survival in BC patients was independent of other well-known prognostic markers such as ERBB2 [55] (Figure 6A, 6B). However, a better prediction of metastasis-free survival in $\mathrm{BC}$ patients was observed when SHARPIN was used in combination with the commonly used marker ERBB2 (Figure 6C) or with other candidate genes (Supplementary Table S2). SHARPIN expression was able to predict metastasis-free survival in BC patients after treatment, and may be useful prognostic indicator for predicting patient survival and for stratifying patients for treatment regimens.

In summary, we describe a powerful approach to identify BC metastasis genes using a replicationincompetent $\gamma \mathrm{RV}$. This approach has broad potential application to identify oncogenic processes for diverse cancers. Identification of the previously validated BC genes WWTR1, RIN1 and also SHARPIN which we validated here, show the potential of our approach. Our results demonstrate that $S H A R P I N$ is a $\mathrm{BC}$ metastasis gene and a prognostic indicator for BC.

\section{MATERIALS AND METHODS}

\section{Cell line, vector production, and transduction}

The MDA-MB-231 cell line (ATCC HTB-26, Rockville, MD, USA) was cultured in Dulbecco's modified eagle medium (DMEM)/high glucose (Thermo Scientific, Waltham, MA, USA) supplemented with $10 \%$ fetal bovine serum (FBS) (Atlanta Biologicals, Lawrenceville, GA, USA) and penicillin/streptomycin at $37^{\circ} \mathrm{C}$ in $5 \% \mathrm{CO}_{2}$. We constructed the $\gamma \mathrm{RV}$ shuttle vector CL-SGN-OK using murine leukemia virus derived long terminal repeats (MLV LTRs) and an internal spleen focus forming virus-derived promoter driving an enhanced green fluorescent protein (EGFP)-neomycin fusion protein [67]. The CL-SGN-OK also contains an R6K $\gamma$ origin of replication and kanamycin resistance gene which were inserted into pCAG-EGFP-PRE, a gift from Fred Gage (Addgene plasmid \# 16664) backbone [68] using standard molecular biology techniques. Concentrated viral stocks pseudotyped with vesicular stomatitis virus glycoprotein envelope were produced by polyethyleneimine transient plasmid transfection of HEK 293T cells using helper plasmids pLGPS and pMD2.G. Viral supernatant was filtered using $0.45 \mu \mathrm{m}$ filter (Pall Life Sciences, Cornwall, UK) and centrifuged for $18 \mathrm{~h}$ at 12,100 g. Viral supernatant was concentrated 100 fold and functional titers were determined by transduction of HT1080 fibrosarcoma cells and analyzed for EGFP expression by flow cytometry.

\section{Generation of mutagenized human MDA-MB-231 cells}

Control and CL-SGN-OK MDA-MB-231 cells transduced at an MOI of 0.2 were cultured in DMEM/ high glucose supplemented with $10 \% \mathrm{FBS}$ and $600 \mu \mathrm{g} /$ $\mathrm{ml}$ of G418 sulfate. Cells were passaged and re-plated 1:2 every 3-4 days for 16 days under G418 selection prior to injection.

\section{Shuttle vector rescue and the identification of proviral integration sites}

The genomic DNA from BC metastases were extracted as previously described [17]. The vector plasmids obtained from the kanamycin resistant colonies were sequenced using a $\gamma \mathrm{RV}$ primer specific to the CL-SGN-OK 3' LTR, (LTR1 - 5' CTTGTGGTCTCGCTGTTCCTTGG $3^{\prime}$ '). The integrated provirus-chromosomal junction was identified and the integration site to human genome (hg38) 
were determined using VISA bioinformatics program [26] and UCSC BLAST Like-Alignment Tool (BLAT) [27].

\section{In vivo $\mathrm{BC}$ metastasis model}

All procedures involving handling of animals were performed according to protocols approved by the Washington State University Institutional Animal Care and Use Committee. A total of ten 6 week old female NOD. Cg-Prkde ${ }^{\text {scid }} I 2 \mathrm{rg}^{\text {tml }}{ }^{\mathrm{Wj}} / \mathrm{SzJ}$ (NSG) mice were obtained from The Jackson Laboratory (Bar Harbor, ME, USA). CLSGN-OK mutagenized or unmutagenized MDA-MB-231 cells were co-transplanted with bone marrow derived hMSCs (Lonza, Walkersville, MD, USA) orthotopically into the mammary fat pad [23] of 8 week old mice. A 5 $\mathrm{mm}$ incision was made in the skin over the abdomen to expose the mammary fat pad and $1 \times 10^{6}$ cells suspended in $50 \mu 1$ Hank's balanced salt solution (HBSS) (Lonza, Walkersville, MD, USA) were injected using a 25 gauge needle into the mammary fat pad. The incision in the skin was closed using surgical tissue glue $3 \mathrm{M}$ Vetbond ${ }^{\mathrm{TM}}$ (St. Paul, MN, USA). The growth of the primary tumor was determined twice a week by external caliper measurement of two orthogonal diameters as described [24] and values were extrapolated to generate the tumor growth curve. The mice were euthanized when the tumor median diameter reached $1.5 \mathrm{~cm}$. At necropsy, primary tumors and EGFP-positive metastasis were dissected, snapfrozen in liquid nitrogen for approximately 10 seconds and stored at $-80^{\circ} \mathrm{C}$. The genomic DNA was extracted from the metastatic tissues using a Qiagen PureGene Cell and Tissue kit (Valencia, CA, USA). Shuttle vector rescue and identification of provirus integration sites was performed as previously described [17]. Briefly, the isolated genomic DNA from BC metastasis was sheared using Hydroshear (DigiLab Inc., Marlborough, MA, USA) and endrepaired using Terminator End Repair Kit (Lucigen Corp., Middleton, WI, USA). The sheared DNA fragments were ligated using T4 DNA Ligase (New England Biolabs Inc., Ipswich, MA, USA) and transformed in E. coli by electroporation (Electroporator 2510, Eppendorf, Westbury, NY, USA) and the rescued kanamycin resistant colonies were sequenced using the $\gamma$ RV LTR1 primer that is specific to the 3' MLV LTR.

\section{Identification and analysis of candidate BC metastasis genes}

Publicly available cDNA microarray datasets in Oncomine ${ }^{\mathrm{TM}}$ were used to assess and analyze gene expression in $\mathrm{BC}$ patient tissues versus normal breast tissues of the same patient tissue type [28]. We queried for expression of candidate genes between $\mathrm{BC}$ vs normal and Oncomine $^{\mathrm{TM}}$ was used to compute differential gene expression. Candidate genes were considered "overexpressed" or "underexpressed" if they were highly expressed or underexpressed in one class relative to the other. P-values for gene expression between $\mathrm{BC}$ vs normal classes was generated using student $t$-test. Pre-computated differential gene expression profiles of candidate genes in each dataset served as an input for meta-analysis. We used 22 datasets for meta-analysis from nine studies [25, 29-37] to evaluate gene expression patterns of the $\gamma \mathrm{RV}$ shuttle vector identified $\mathrm{BC}$ metastasis genes within $5 \mathrm{~kb}$ of provirus integration sites. A total of 2,691 BC samples and 200 normal breast tissue samples were used. We analyzed statistical data from five Oncomine ${ }^{\mathrm{TM}}$ studies with information on primary vs metastasis to assess whether SHARPIN, our top candidate gene is overexpressed in metastatic tumors. The five cohort studies were the only ones with information on primary and metastatic tumors in Oncomine ${ }^{\mathrm{TM}}$. Also, we assessed if the expression of SHARPIN levels correlated with ERBB2 BC clinico-pathology by interrogating Gluck et al dataset [30]. The online cBioportal cancer genomics tool (http://www.cbioportal.org/) was used to characterize the genetic alterations of the identified $\mathrm{BC}$ metastasis genes in patients using TCGA dataset [43, 44]. Using the same dataset we assessed whether the most altered gene is associated with any known $\mathrm{BC}$ clinico-pathological features such as ERBB2, ER, and node tumors. The SurvExpress online biomarker tool [53] was used to predict the clinical outcome and prognostic value of $\mathrm{BC}$ metastasis genes. We searched for mRNA expression across 31 available $\mathrm{BC}$ mRNA datasets using candidate genes as searching criteria. We identified five cohorts that included mRNA levels from all candidate genes identified. Of them, we used Kao et al. [54] microarray patient dataset (GSE20685) that had highest sample size (327 patients) and stratified patients based on metastasis risk following adjuvant therapy. We obtained results using average score from probe sets and the default quantilenormalized format. We set the statistical analysis and graphical outputs using available datasets endpoints to obtain two maximized risk groups. Kaplan-Meier survival curves of censored Cox survival analysis was generated and log-rank statistical test performed with significance at 95\% confidence level. P-values for the box-plots depicting the difference in gene expression was generated using t-test. We compared SHARPIN with an independent wellestablished Oncotype DX® BC biomarker ERBB2 [55, 69] to predict $B C$ progression using the same dataset. To further show the involvement of SHARPIN in metastasis we interrogated SHARPIN expression in an independent dataset by Chin et al. [56] that measured gene expression profiles for $130 \mathrm{BC}$ patient tumors after standard treatment. 


\section{Generation of SHARPIN knockdown cells}

SHARPIN knockdown cells were generated by transducing MDA-MB-231Luc2 cells (PerkinElmer, Hopkinton, MA, USA) with doxycycline inducible TRIPZ lentivirus vectors that express shRNAs targeting human SHARPIN (GE Healthcare, Lafayette, CO, USA). The sequence for SHARPIN shRNA 1 was 5, TGATGAAGGTGCAGGAAGG 3' and shRNA 2 was 5' TTGATGAAGGTGCAGGAAG 3'. BC cells were transduced with SHARPIN lentiviral shRNA at MOI of 5 , puromycin selected and $2 \mu \mathrm{g} / \mathrm{mL}$ doxycycline (Sigma Aldrich, St. Louis, MO, USA) was added to the media to induce shRNA knockdown. Transduction efficiency was assessed by measuring red fluorescence protein (RFP) with fluorescence microscopy and flow cytometry after 72 h. Transduced cells were selected for and maintained in 1 $\mu \mathrm{g} / \mathrm{mL}$ puromycin. SHARPIN knockdown was confirmed in all cases by Western blot. $20 \mu \mathrm{g}$ MDA-MB-231 whole-cell lysates of knockdown and control cells were used to determine the expression level of SHARPIN protein. Polyvinyl difluoride (PVDF) transfer membrane was incubated with SHARPIN antibody (D4P5B, Cell Signaling Technology, Danvers, MA, USA). Based on the evaluation of SHARPIN expression by Western blot (Figure 5A), SHARPIN lentiviral shRNA 2 was chosen for clonogenic and in vivo knockdown studies.

\section{Clonogenic assay}

The clonogenic assay has been previously described $[70,71]$. Briefly, MDA-MB-231 cells with an inducible SHARPIN shRNA were seeded in 6-well plates at $5 \times 10^{2}$ cells/well and cultured for 12 days. The colony formation ability of each cell in media supplemented with or without doxycycline $(2 \mu \mathrm{g} / \mathrm{mL})$ was determined in triplicate. Cells were washed with phosphate buffered saline (PBS), fixed with methanol and stained with $0.5 \%$ crystal violet for 20 30 minutes at room temperature. Cells were washed three times with water and air dried. Colonies (> 100 cells) were counted in each well.

\section{Validation using inducible lentiviral-mediated knockdown in the in vivo xenotransplant model}

Mice studies were performed according to protocols approved by the Washington State University Institutional Animal Care and Use Committee. For in vivo SHARPIN metastasis studies, puromycin selected transduced cells were injected into an 8 week old immunodeficient mice via lateral tail vein. For induction of shRNA expression the shSHARPIN mice group $(n=5)$ received $2 \mathrm{mg} / \mathrm{mL}$ doxycycline (+ DOX) in drinking water ad libitum whereas the control group $(n=5)$ received only drinking water (-
DOX). IVIS ${ }^{\mathrm{TM}} 100$ Imaging System (Xenogen, Alameda, CA, USA) was used for whole body imaging after 150 $\mathrm{mg} / \mathrm{kg}$ D-luciferin (Caliper Life Science, Hopkinton, MA, USA) intraperitoneum administration. The animal was placed in IVIS imaging chamber and imaging was completed between 5-10 minutes after injection. Living image Software 2.50 (Perkin Elmer, Hopkinton, MA, USA) was used to quantify the image luminescence intensities. Luminescence intensities were measured for each mouse by specifying regions of interest (ROIs) using a rectangular drawing encompassing the thorax of each animal in dorsal recumbence position. Photon values were acquired and the mean bioluminescence intensity for SHARPIN knockdown $(n=5)$ and control $(n=3)$ group were determined.

\section{Statistical analysis}

Statistical analysis was performed with Student's t-test. Values were expressed as means $\pm \mathrm{SD} / \mathrm{SEM}$. $P$-values of $<0.05$ were considered significant.

\section{ACKNOWLEDGMENTS}

This work was supported by NIH grant CA173598 and by the Department of Defense Peer Reviewed Cancer Research Program under award number W81XWH-11-1-0576. Views and opinions of, and endorsements by the author(s) do not reflect those of the US Army or the Department of Defense.

\section{CONFLICTS OF INTEREST} interest.

Authors declare that they have no competing

\section{Editorial note}

This paper has been accepted based in part on peerreview conducted by another journal and the authors' response and revisions as well as expedited peer-review in Oncotarget.

\section{REFERENCES}

1. Feuer EJ, Wun LM, Boring CC, Flanders WD, Timmel MJ and Tong $\mathrm{T}$. The lifetime risk of developing breast cancer. J Natl Cancer Inst. 1993; 85:892- 897.

2. Society AC. (2013). Breast Cancer Facts \& Figures 20132014. (Atlanta: American Cancer Society, Inc. 2013).

3. Shadeo A and Lam WL. Comprehensive copy number profiles of breast cancer cell model genomes. Breast Cancer Res. 2006; 8:R9.

4. Zhao Q, Caballero OL, Levy S, Stevenson BJ, Iseli C, 
de Souza SJ, Galante PA, Busam D, Leversha MA, Chadalavada K, Rogers YH, Venter JC, Simpson AJ, et al. Transcriptome-guided characterization of genomic rearrangements in a breast cancer cell line. Proc Natl Acad Sci U S A. 2009; 106:1886-1891.

5. Stratton MR, Campbell PJ and Futreal PA. The cancer genome. Nature. 2009; 458:719-724.

6. Network CGA. Comprehensive molecular portraits of human breast tumours. Nature. 2012; 490:61-70.

7. Ledford H. (2010). Big science: The cancer genome challenge. Nature. (England, pp. 972-974.

8. Kalyana-Sundaram S, Shankar S, DeRoo S, Iyer MK, Palanisamy N, Chinnaiyan AM and Kumar-Sinha C. Gene Fusions Associated with Recurrent Amplicons Represent a Class of Passenger Aberrations in Breast Cancer. Neoplasia. 2012; 14:702-+.

9. Zhang J, Liu J, Sun J, Chen C, Foltz G and Lin B. Identifying driver mutations from sequencing data of heterogeneous tumors in the era of personalized genome sequencing. Briefings in Bioinformatics. 2014; 15:244-255.

10. Hartmaier RJ, Priedigkeit N and Lee AV. Who's driving anyway? Herculean efforts to identify the drivers of breast cancer. Breast Cancer Research. 2012; 14.

11. Uren AG, Kool J, Berns A and van Lohuizen M. Retroviral insertional mutagenesis: past, present and future. Oncogene. $2005 ; 24: 7656-7672$.

12. Trobridge GD. Genotoxicity of retroviral hematopoietic stem cell gene therapy. Expert Opin Biol Ther. 2011; 11:581-593.

13. Lund AH, Turner G, Trubetskoy A, Verhoeven E, Wientjens E, Hulsman D, Russell R, DePinho RA, Lenz J and van Lohuizen M. Genome-wide retroviral insertional tagging of genes involved in cancer in Cdkn2a-deficient mice. Nature Genetics. 2002; 32:160-165.

14. Collier LS, Carlson CM, Ravimohan S, Dupuy AJ and Largaespada DA. Cancer gene discovery in solid tumours using transposon-based somatic mutagenesis in the mouse. Nature. 2005; 436:272-276.

15. Landrette SF and Xu T. Somatic genetics empowers the mouse for modeling and interrogating developmental and disease processes. PLoS genetics. 7:e1002110.

16. Ranzani M, Cesana D, Bartholomae CC, Sanvito F, Pala M, Benedicenti F, Gallina P, Sergi LS, Merella S, Bulfone A, Doglioni C, von Kalle C, Kim YJ, et al. Lentiviral vectorbased insertional mutagenesis identifies genes associated with liver cancer. Nat Methods. 2013; 10:155-161.

17. Schinke EN, Bii V, Nalla A, Rae DT, Tedrick L, Meadows GG and Trobridge GD. A novel approach to identify driver genes involved in androgen-independent prostate cancer. Molecular cancer. 2014; 13:120.

18. Hacein-Bey-Abina S, Von Kalle C, Schmidt M, McCormack MP, Wulffraat N, Leboulch P, Lim A, Osborne CS, Pawliuk R, Morillon E, Sorensen R, Forster A, Fraser $\mathrm{P}$, et al. LMO2-associated clonal $\mathrm{T}$ cell proliferation in two patients after gene therapy for SCID-X1. Science. 2003; 302:415-419.

19. Hacein-Bey-Abina S, Garrigue A, Wang GP, Soulier J, Lim A, Morillon E, Clappier E, Caccavelli L, Delabesse E, Beldjord K, Asnafi V, MacIntyre E, Dal Cortivo L, et al. Insertional oncogenesis in 4 patients after retrovirusmediated gene therapy of SCID-X1. The Journal of clinical investigation. 2008; 118:3132-3142.

20. Wu C, Jares A, Winkler T, Xie J, Metais J-Y and Dunbar CE. High Efficiency Restriction Enzyme-Free Linear Amplification-Mediated Polymerase Chain Reaction Approach for Tracking Lentiviral Integration Sites Does Not Abrogate Retrieval Bias. Human Gene Therapy. 2013; 24:38-47.

21. Trobridge GD, Miller DG, Jacobs MA, Allen JM, Kiem HP, Kaul R and Russell DW. Foamy virus vector integration sites in normal human cells. Proceedings of the National Academy of Sciences of the United States of America. 2006; 103:1498-1503.

22. Montini E, Cesana D, Schmidt M, Sanvito F, Bartholomae CC, Ranzani M, Benedicenti F, Sergi LS, Ambrosi A, Ponzoni M, Doglioni C, Di Serio C, von Kalle C, et al. The genotoxic potential of retroviral vectors is strongly modulated by vector design and integration site selection in a mouse model of HSC gene therapy. The Journal of clinical investigation. 2009; 119:964-975.

23. Price JE, Polyzos A, Zhang RD and Daniels LM. Tumorigenicity and metastasis of human breast carcinoma cell lines in nude mice. Cancer Res. 1990; 50:717- 721.

24. Zhang RD, Fidler IJ and Price JE. Relative malignant potential of human breast carcinoma cell lines established from pleural effusions and a brain metastasis. Invasion Metastasis. 1991; 11:204-215.

25. Karnoub AE, Dash AB, Vo AP, Sullivan A, Brooks MW, Bell GW, Richardson AL, Polyak K, Tubo R and Weinberg RA. Mesenchymal stem cells within tumour stroma promote breast cancer metastasis. Nature. 2007; 449:557-563.

26. Hocum JD, Battrell LR, Maynard R, Adair JE, Beard BC, Rawlings DJ, Kiem HP, Miller DG and Trobridge GD. VISA - Vector Integration Site Analysis server: a webbased server to rapidly identify retroviral integration sites from next- generation sequencing. BMC Bioinformatics. $2015 ; 16: 212$.

27. Kent WJ. BLAT - the BLAST-like alignment tool. Genome Res. 2002; 12:656- 664.

28. Rhodes DR, Kalyana-Sundaram S, Mahavisno V, Varambally R, Yu J, Briggs BB, Barrette TR, Anstet MJ, Kincead-Beal C, Kulkarni P, Varambally S, Ghoshy D and Chinnaiyan AM. Oncomine 3.0: Genes, pathways, and networks in a collection of 18,000 cancer gene expression profiles. Neoplasia. 2007; 9:166- 180.

29. Curtis C, Shah SP, Chin SF, Turashvili G, Rueda OM, Dunning MJ, Speed D, Lynch AG, Samarajiwa S, Yuan Y, Graf S, Ha G, Haffari G, et al. The genomic and 
transcriptomic architecture of 2,000 breast tumours reveals novel subgroups. Nature. 2012; 486:346-352.

30. Gluck S, Ross JS, Royce M, McKenna EF, Jr., Perou CM, Avisar E and Wu L. TP53 genomics predict higher clinical and pathologic tumor response in operable earlystage breast cancer treated with docetaxel-capecitabine +/trastuzumab. Breast Cancer Res Treat. 2012; 132:781-791.

31. Ma XJ, Dahiya S, Richardson E, Erlander M and Sgroi DC. Gene expression profiling of the tumor microenvironment during breast cancer progression. Breast Cancer Res. 2009; 11:R7.

32. Perou CM, Sorlie T, Eisen MB, van de Rijn M, Jeffrey SS, Rees CA, Pollack JR, Ross DT, Johnsen H, Akslen LA, Fluge O, Pergamenschikov A, Williams C, et al. Molecular portraits of human breast tumours. Nature. 2000; 406:747752.

33. Radvanyi L, Singh-Sandhu D, Gallichan S, Lovitt C, Pedyczak A, Mallo G, Gish K, Kwok K, Hanna W, Zubovits J, Armes J, Venter D, Hakimi J, et al. The gene associated with trichorhinophalangeal syndrome in humans is overexpressed in breast cancer. Proc Natl Acad Sci U S A. 2005; 102:11005-11010.

34. Richardson AL, Wang ZC, De Nicolo A, Lu X, Brown M, Miron A, Liao X, Iglehart JD, Livingston DM and Ganesan S. X chromosomal abnormalities in basal-like human breast cancer. Cancer Cell. 2006; 9:121-132.

35. Sorlie T, Perou CM, Tibshirani R, Aas T, Geisler S, Johnsen $\mathrm{H}$, Hastie T, Eisen MB, van de Rijn M, Jeffrey SS, Thorsen T, Quist H, Matese JC, et al. Gene expression patterns of breast carcinomas distinguish tumor subclasses with clinical implications. Proc Natl Acad Sci U S A. 2001; 98:1086910874.

36. Sorlie T, Tibshirani R, Parker J, Hastie T, Marron JS, Nobel A, Deng S, Johnsen H, Pesich R, Geisler S, Demeter J, Perou CM, Lonning PE, et al. Repeated observation of breast tumor subtypes in independent gene expression data sets. Proc Natl Acad Sci U S A. 2003; 100:8418-8423.

37. Zhao H, Langerod A, Ji Y, Nowels KW, Nesland JM, Tibshirani R, Bukholm IK, Karesen R, Botstein D, Borresen-Dale AL and Jeffrey SS. Different gene expression patterns in invasive lobular and ductal carcinomas of the breast. Mol Biol Cell. 2004; 15:2523-2536.

38. Bartucci M, Dattilo R, Moriconi C, Pagliuca A, Mottolese M, Federici G, Benedetto AD, Todaro M, Stassi G, Sperati F, Amabile MI, Pilozzi E, Patrizii M, et al. TAZ is required for metastatic activity and chemoresistance of breast cancer stem cells. Oncogene. 2014.

39. Milstein M, Mooser CK, Hu H, Fejzo M, Slamon D, Goodglick L, Dry S and Colicelli J. RIN1 is a breast tumor suppressor gene. Cancer Research. 2007; 67:11510-11516.

40. Cleator S, Heller W and Coombes RC. Triple-negative breast cancer: therapeutic options. Lancet Oncol. 2007; 8:235-244.

41. Al-Kuraya K, Schraml P, Torhorst J, Tapia C, Zaharieva B,
Novotny H, Spichtin H, Maurer R, Mirlacher M, Köchli O, Zuber M, Dieterich H, et al. Prognostic relevance of gene amplifications and coamplifications in breast cancer. Cancer Res. 2004; 64:8534-8540.

42. Pollack JR, Sørlie T, Perou CM, Rees CA, Jeffrey SS, Lonning PE, Tibshirani R, Botstein D, Børresen-Dale AL and Brown PO. Microarray analysis reveals a major direct role of DNA copy number alteration in the transcriptional program of human breast tumors. Proc Natl Acad Sci U S A. 2002; 99:12963-12968.

43. Cerami E, Gao J, Dogrusoz U, Gross BE, Sumer SO, Aksoy BA, Jacobsen A, Byrne CJ, Heuer ML, Larsson E, Antipin Y, Reva B, Goldberg AP, et al. The cBio Cancer Genomics Portal: An Open Platform for Exploring Multidimensional Cancer Genomics Data. Cancer Discovery. 2012; 2:401404.

44. Gao J, Aksoy BA, Dogrusoz U, Dresdner G, Gross B, Sumer SO, Sun Y, Jacobsen A, Sinha R, Larsson E, Cerami E, Sander C and Schultz N. Integrative Analysis of Complex Cancer Genomics and Clinical Profiles Using the cBioPortal. Science Signaling. 2013; 6.

45. Zhang Y, Huang H, Zhou H, Du T, Zeng L, Cao Y, Chen J, Lai Y, Li J, Wang G and Guo Z. Activation of Nuclear Factor kappa B Pathway and Downstream Targets Survivin and Livin by SHARPIN Contributes to the Progression and Metastasis of Prostate Cancer. Cancer. 2014; 120:32083218.

46. De Melo J and Tang D. Elevation of SIPL1 (SHARPIN) Increases Breast Cancer Risk. PLoS One. 2015; 10:e0127546.

47. van de Wetering M, Oving I, Muncan V, Fong MTP, Brantjes H, van Leenen D, Holstege FCP, Brummelkamp TR, Agami $\mathrm{R}$ and Clevers H. Specific inhibition of gene expression using a stably integrated, inducible small-interfering-RNA vector. Embo Reports. 2003; 4(6):609-615.

48. Gupta GP and Massagué J. Cancer metastasis: building a framework. Cell. 2006; 127:679-695.

49. Fidler IJ. Timeline - The pathogenesis of cancer metastasis: the 'seed and soil' hypothesis revisited. Nature Reviews Cancer. 2003; 3:453-458.

50. Han HJ, Russo J, Kohwi Y and Kohwi-Shigematsu T. SATB1 reprogrammes gene expression to promote breast tumour growth and metastasis. Nature. 2008; 452:187-193.

51. Prescher JA and Contag $\mathrm{CH}$. Guided by the light: visualizing biomolecular processes in living animals with bioluminescence. Curr Opin Chem Biol. 2010; 14:80-89.

52. Ludwig JA and Weinstein JN. Biomarkers in cancer staging, prognosis and treatment selection. Nature Reviews Cancer. 2005; 5:845-856.

53. Aguirre-Gamboa R, Gomez-Rueda H, Martinez-Ledesma E, Martinez-Torteya A, Chacolla-Huaringa R, RodriguezBarrientos A, Tamez-Pena JG and Trevino V. SurvExpress: an online biomarker validation tool and database for cancer gene expression data using survival analysis. PloS one. 
2013; 8:e74250.

54. Kao KJ, Chang KM, Hsu HC and Huang AT. Correlation of microarray-based breast cancer molecular subtypes and clinical outcomes: implications for treatment optimization. BMC Cancer. 2011; 11:143.

55. Conlin AK and Seidman AD. Use of the Oncotype DX 21gene assay to guide adjuvant decision making in early-stage breast cancer. Mol Diagn Ther. 2007; 11:355-360.

56. Chin K, DeVries S, Fridlyand J, Spellman PT, Roydasgupta R, Kuo WL, Lapuk A, Neve RM, Qian Z, Ryder T, Chen F, Feiler H, Tokuyasu T, et al. Genomic and transcriptional aberrations linked to breast cancer pathophysiologies. Cancer Cell. 2006; 10:529-541.

57. Al-Ejeh F, Simpson PT, Saunus JM, Klein K, Kalimutho M, Shi W, Miranda M, Kutasovic J, Raghavendra A, Madore J, Reid L, Krause L, Chenevix-Trench G, et al. Meta-analysis of the global gene expression profile of triple-negative breast cancer identifies genes for the prognostication and treatment of aggressive breast cancer. Oncogenesis. 2014; 3:e124.

58. Ping Z, Siegal GP, Almeida JS, Schnitt SJ and Shen D. Mining genome sequencing data to identify the genomic features linked to breast cancer histopathology. J Pathol Inform. 2014; 5:3.

59. Seymour RE, Hasham MG, Cox GA, Shultz LD, Hogenesch H, Roopenian DC and Sundberg JP. Spontaneous mutations in the mouse Sharpin gene result in multiorgan inflammation, immune system dysregulation and dermatitis. Genes Immun. 2007; 8:416-421.

60. Ikeda F, Deribe YL, Skanland SS, Stieglitz B, Grabbe C, Franz-Wachtel M, van Wijk SJ, Goswami P, Nagy V, Terzic J, Tokunaga F, Androulidaki A, Nakagawa T, et al. SHARPIN forms a linear ubiquitin ligase complex regulating NF-kappaB activity and apoptosis. Nature. 2011; 471:637-641.

61. Tokunaga F, Nakagawa T, Nakahara M, Saeki Y, Taniguchi M, Sakata S-i, Tanaka K, Nakano H and Iwai K. SHARPIN is a component of the NF-kappa B- activating linear ubiquitin chain assembly complex. Nature. 2011; 471:633U113.

62. Wang Z, Potter CS, Sundberg JP and Hogenesch H. SHARPIN is a key regulator of immune and inflammatory responses. Journal of Cellular and Molecular Medicine. 2012; 16:2271-2279.

63. Sieber S, Lange N, Kollmorgen G, Erhardt A, Quaas A, Gontarewicz A, Sass G, Tiegs G and Kreienkamp H-J. Sharpin Contributes to TNF alpha Dependent NF kappa B Activation and Anti-Apoptotic Signalling in Hepatocytes. Plos One. 2012; 7.

64. McGowan HW, Schuijers JA, Grills BL, McDonald SJ, Rickard JA, Silke J and McDonald AC. Sharpin is a key regulator of skeletal homeostasis in a TNF- dependent manner. Journal of Musculoskeletal \& Neuronal Interactions. 2014; 14:454-463.
65. Li Y, Li J, Mao Y, Li X, Liu W, Xu L, Han Y and Wang $H$. The alteration of SHARPIN expression in the mouse brainstem during herpes simplex virus 1 - induced facial palsy. Neuroscience Letters. 2015; 586:50-54.

66. Pouwels J, Nevo J, Pellinen T, Ylanne J and Ivaska J. Negative regulators of integrin activity. Journal of Cell Science. 2012; 125:3271-3280.

67. Weber K, Mock U, Petrowitz B, Bartsch U and Fehse B. Lentiviral gene ontology (LeGO) vectors equipped with novel drug-selectable fluorescent proteins: new building blocks for cell marking and multi-gene analysis. Gene Therapy. 2010; 17:511-520.

68. Zhao C, Teng EM, Summers RG, Ming GL and Gage FH. Distinct morphological stages of dentate granule neuron maturation in the adult mouse hippocampus. J Neurosci. 2006; 26:3-11.

69. Kok M, Linn SC, Van Laar RK, Jansen MP, van den Berg TM, Delahaye LJ, Glas AM, Peterse JL, Hauptmann M, Foekens JA, Klijn JG, Wessels LF, Van't Veer LJ, et al. Comparison of gene expression profiles predicting progression in breast cancer patients treated with tamoxifen. Breast Cancer Res Treat. 2009; 113:275-283.

70. Al-Hajj M, Wicha MS, Benito-Hernandez A, Morrison SJ and Clarke MF. Prospective identification of tumorigenic breast cancer cells. Proceedings of the National Academy of Sciences of the United States of America. 2003; 100:39833988.

71. Franken NAP, Rodermond HM, Stap J, Haveman J and van Bree C. Clonogenic assay of cells in vitro. Nature Protocols. 2006; 1:2315-2319. 